\title{
Comparison of antisera in the fluorescent antibody test for detection of Bacteroides spp in clinical specimens
}

\author{
A Wills, Elizabeth TAYlor,* ANNAlisa PANTOSTI, I PHILlips,* \\ SOAD TABAQCHALI
}

From the Departments of Medical Microbiology, St Bartholomew's Hospital and *St Thomas' Hospital, London

SUMMARY Twenty-two known strains of the Bacteroides fragilis group of organisms and 67 clinical specimens from 'a variety of sites were examined by fluorescent antibody test (IFA) using two different antisera for the rapid detection of $\boldsymbol{B}$ fragilis group of organisms.

A previously reported Barts' pooled antisera was compared with a commercially produced Fluoretec kit antisera and the findings were related to routine anaerobic culture and gas liquid chromatography for short chain fatty acids.

The Barts' antisera was more sensitive (88\%) but less specific $(88 \%)$ than the kit (sensitivity $50 \%$, specificity $98 \%$ ). This indicates that Barts' antisera picks up more positive cultures than the kit. The predictive value of a positive test was $82 \%$ for Barts' antisera and $93 \%$ for the kit. There were higher numbers of false-negatives with the kit (13/26) than with the Barts' (3/26). The predictive value of a negative test was $92 \%$ for Barts' antisera and $75 \%$ for the kit, indicating that a negative IFA test with Barts' antisera is a reliable index of the absence of the $B$ fragilis group of organisms from clinical specimens. The implications for the use of this test in a routine laboratory are discussed.

With improved laboratory techniques anaerobic bacteria have been increasingly shown to be of great importance in a wide range of infections. ${ }^{1-3}$ The Bacteroides fragilis group of organisms is the commonest anaerobic species isolated from purulent material. ${ }^{4}$ Treatment of such infections is often effective if instituted early but cultural techniques are slow and may not give a clinically useful result in time. A rapid and reliable method of diagnosis which can be incorporated into the routine procedures of most clinical bacteriology laboratories is required. Immunofluorescence may provide such a method using equipment readily available to many laboratories. ${ }^{6-8}$ The use of two antisera for the detection of $B$ fragilis infections by the indirect fluorescent antibody (IFA) test has been reported by this laboratory at St Bartholomew's Hospital. ${ }^{9}$ Recently a commercial IFA test kit (Fluoretec-F) has been marketed and evaluated in the USA ${ }^{10}$ and Belgium. ${ }^{11}$ We have tested the kit in parallel with our pooled Barts' antisera previously studied in this laboratory. ${ }^{9}$

Accepted for publication 15 July 1981

\section{Material and methods}

BACTERIAL STRAINS

Twenty-two known Bacteroides strains belonging to the $B$ fragilis group were used in this study.

These included:

13 strains of $B$ fragilis (5 NCTC strains and 8 clinical isolates)

5 strains of $B$ distasonis (ATCC 8503 and 4 faecal isolates)

2 strains of $B$ vulgatus (NCTC 10583 and 11154)

1 strain of $B$ thetaiotaomicron (NCTC 10582)

1 strain of $B$ ovatus (ATCC 8483)

A heavy inoculum of each strain was taken from an overnight growth on DST agar (Oxoid), added to $10 \mathrm{ml}$ peptone-yeast-glucose (PYG) broth and incubated anaerobically at $37^{\circ} \mathrm{C}$ for $24 \mathrm{~h}$. This culture was centrifuged and washed three times in phosphatebuffered saline (PBS) pH 7·2.

\section{CLINICAL SPECIMENS}

Sixty-seven clinical specimens were examined. These were collected from patients in St Bartholomew's Hospital and St Thomas' Hospital, London, in whom 
an anaerobic component of infection was suspected (see Table 2).

All specimens were cultured aerobically (horse blood agar and MacConkey) and anaerobically (neomycin $70 \mathrm{mg} / \mathrm{l}$, blood agar or nalidixic acid $10 \mathrm{mg} / \mathrm{l}$ blood agar, both supplemented with menadione and haemin). Anaerubic culture was carried out in a glove box with an anaerobic atmosphere (nitrogen $80 \%$, hydrogen $10 \%$ and carbon dioxide $10 \%$ ). Identification of organisms was carried out according to methods in the VPI manual. ${ }^{12}$ Bacterial culture and immunofluorescence were carried out by separate workers and results correlated at the end of the study. Clinical specimens were also analysed by gas-liquid chromatography (GLC) for the presence of short chain fatty acids.

\section{IMMUNOFLUORESCENCE}

Fluoretec-F kit (Pfizer Inc, New York) was used according to the manufacturer's instructions. A light smear of the washed organisms or purulent specimens was made with a swab on a clean slide over an inscribed circle of $1 \mathrm{~cm}$ diameter. After drying in air the smear was fixed by very gentle heating and treated with rhodamine-conjugated globulin prestain for $15 \mathrm{~min}$ at room temperature in a moist chamber. The prestain was removed by blotting and replaced with anti- $B$ fragilis group polyvalent conjugate. After incubation for $30 \mathrm{~min}$ at room temperature this was removed by washing in distilled water. The slides were allowed to dry and mounted under a cover slip.

Smears were also made on a Teflon-coated slide bearing $6 \mathrm{~mm}$ diameter wells (C A Hendley (Essex) Ltd). These smears were also fixed by gentle heating and treated with Barts' pooled preparation of wholecell antisera ${ }^{13}$ of different $B$ fragilis somatic serotypes in a dilution of $1 / 32$, as previously described. ${ }^{9}$ The smears were incubated at room temperature in a moist chamber for $30 \mathrm{~min}$ and washed in PBS for $10 \mathrm{~min}$. Goat antirabbit immunoglobulin conjugated with fluorescein isothiocyanate (Behringwerke AG, Marburg) diluted 1/10 in PBS was then added to each well and incubated for a further 30 min at room temperature. After thorough washing in PBS for $10 \mathrm{~min}$ and drying, the slides were mounted with buffered glycerol pH 8.5 under a coverslip $(22 \times 56 \mathrm{~mm})$.

\section{MICROSCOPY}

Both sets of slides were examined for fluorescent organisms using a Leitz Ortholux II incident light fluorescent microscope illuminated by a $50 \mathrm{~W}$ ultrahigh pressure mercury vapour lamp with BG38 red suppression filter and KP500 selective excitation filter. All specimens were viewed with $\times 40$ dry objective, and the IFA kit slides were also read using $\times 100$ oil immersion objective as recommended by the manufacturers.

Statistical analysis were determined by the method of Vecchio. ${ }^{14}$

Sensitivity = culture-positive specimens with positive IFA/all culture positive specimens tested.

Specificity = culture-negative specimens with negative IFA/all culture negative specimens tested.

The predictive values of a positive and a negative test were also determined by the above method. ${ }^{14}$

\section{Results}

The results of the study of 22 known stock strains are shown in Table 1. The kit and the Barts' pooled whole-cell antiserum show broadly comparable results. The kit failed to detect the two strains of $B$ vulgatus while the Barts' antiserum missed one of these and one strain of $B$ distasonis.

Table 1 Results of immunofluorescence on 22 known strains of the $B$ fragilis group

\begin{tabular}{|c|c|c|c|}
\hline \multirow[t]{2}{*}{ Species } & \multirow{2}{*}{$\begin{array}{l}\text { No strains } \\
\text { tested }\end{array}$} & \multicolumn{2}{|c|}{ No of stains IFA-positive } \\
\hline & & $\begin{array}{l}\text { Barts' pooled } \\
\text { whole-cell antiserum }\end{array}$ & $\begin{array}{l}\text { Fluorotec-F } \\
\text { kit }\end{array}$ \\
\hline $\begin{array}{l}\text { B fragilis } \\
B \text { thetaiotaomicron } \\
B \text { vulgatus } \\
B \text { ovatus } \\
B \text { distasonis }\end{array}$ & $\begin{array}{r}13 \\
1 \\
2 \\
1 \\
5\end{array}$ & $\begin{array}{r}13 \\
1 \\
1 \\
1 \\
4\end{array}$ & $\begin{array}{r}13 \\
1 \\
0 \\
1 \\
5\end{array}$ \\
\hline Total & 22 & 20 & 20 \\
\hline
\end{tabular}

Of the 67 clinical specimens, 35 were negative on IFA and culture for $\boldsymbol{B}$ fragilis group of organisms. Twenty-six yielded $B$ fragilis or Bacteroides spp on culture (Table 2). The latter group includes the five members of the $B$ fragilis group of organisms but excludes the $B$ melaninogenicus group, $B$ oralis and $B$ ureolyticus.

The Barts' antiserum had the greater sensitivity $(88 \%)$ compared with the kit $(50 \%)$ suggesting that the Barts' antisera picks up more positives than the kit (Table 3).

The kit had higher specificity $(98 \%)$ compared with the Barts' antisera ( $88 \%$ ), but the kit gave 13 false-negative results and one false-positive, whereas the Barts' antisera failed to detect three culture-positive specimens but gave false-positive results with five specimens.

The predictive value positive (PV-pos) that is, the likelihood that a subject with a positive IFA test will actually have infection with the $B$ fragilis group, was $82 \%$ and $93 \%$ for Barts' and kit antisera 
Table 2 Results of immunofluorescent assay (IFA), gas-liquid chromatography (GLC) and bacteriological culture on 32 clinical specimens

\begin{tabular}{|c|c|c|c|c|c|c|}
\hline \multicolumn{2}{|c|}{ Specimen } & \multirow[t]{2}{*}{$G L C$} & \multicolumn{2}{|l|}{ IFA using: } & \multicolumn{2}{|l|}{ Organisms isolated } \\
\hline No & Source & & Barts' antisera & Kit antisera & B fragilis group & Other organisms \\
\hline 1 & Paracolic abscess & + & $\div$ & + & $B$ fragilis & - \\
\hline 2 & Abdominal wound & i- & + & + & $B$ vulgatus & B asaccharolyticus \\
\hline 3 & Appendix abscess & ND & + & 4 & B thetaiotaomicron & $\begin{array}{l}C \text { ramosum } \\
\text { Bacteroides (not fragilis group) }\end{array}$ \\
\hline 4 & Groin abscess & - & + & + & B fragilis & - \\
\hline 5 & Diverticular abscess & + & + & + & $B$ vulgatus & $\begin{array}{l}\text { Ps anaerobius } \\
\text { Peptococcus } \\
\text { E alactolyticum } \\
\text { C ramosum } \\
\text { B asaccharolyticus }\end{array}$ \\
\hline 6 & Loin abscess & + & + & + & $\begin{array}{l}\text { B fragilis } \\
B \text { thetaiotaomicron }\end{array}$ & $\begin{array}{l}\text { Ps anaerobius } \\
\text { B eggerthii } \\
\text { Peptococcus }\end{array}$ \\
\hline 7 & High vaginal swab & ND & $\div$ & $-1-$ & Bacteroides sp & - \\
\hline 8 & Wound swab & ND & 4 & + & Bacteroides sp & $\overline{-}$ \\
\hline 9 & Maxillary sinus & + & + & + & Bacteroides sp & $\begin{array}{l}\text { Peptococcus } \\
\text { Staph epidermidis } \\
\text { Pneumococcus }\end{array}$ \\
\hline 10 & Sacral abscess & $\therefore$ & + & + & B fragilis & $\begin{array}{l}\text { Proteus } \\
\text { Enterococcus }\end{array}$ \\
\hline 11 & Axillary abscess & + & + & + & $B$ fragilis & $\begin{array}{l}B \text { asaccharolyticus } \\
B \text { ureolyticus } \\
P \text { s anaerobius } \\
P \text { prevotii }\end{array}$ \\
\hline 12 & $\begin{array}{l}\text { Peritoneal fluid } \\
\text { (acute appendix) }\end{array}$ & + & $\because$ & + & $\begin{array}{l}B \text { fragilis } \\
B \text { ovatus }\end{array}$ & $\begin{array}{l}\text { C clostridiiforme } \\
\text { Veillonella } \\
\text { Peptostreptococcus } \\
\text { Propionobacterium }\end{array}$ \\
\hline 13 & Pelvic abscess & + & + & - & B fragilis & $\begin{array}{l}\text { B asaccharolyticus } \\
F \text { varium } \\
\text { Strep milleri } \\
\text { Ps anaerobius }\end{array}$ \\
\hline 14 & Groin wound pus & + & + & - & Bacteroides sp & $\begin{array}{l}\text { Peptococcus } \\
\text { Enterococcus }\end{array}$ \\
\hline 15 & Wound pus & ND & -+ & - & $B$ fragilis & $\begin{array}{l}\text { Microaerophilic strep } \\
\text { Coliform }\end{array}$ \\
\hline 16 & Frontal lobe abscess & $\because$ & - & - & Bacteroides sp & Peptococcus \\
\hline 17 & Frontal sinus & + & + & - & Bacteroides sp & Peptococcus \\
\hline 18 & Buttock abscess & + & + & - & Bacteroides sp & $\begin{array}{l}\text { Microaerophilic strep } \\
\text { Peptostreptococcus } \\
\text { Corynebacterium }\end{array}$ \\
\hline 19 & Ascitic fluid & t & + & - & $\begin{array}{l}B \text { fragilis } \\
B \text { ovatus }\end{array}$ & $\begin{array}{l}\text { B ruminicola ss brevis } \\
\text { Veillonella } \\
\text { P prevotii } \\
\text { B asaccharolyticus } \\
P \text { acnes } \\
\text { Peptostreptococcus } \\
F \text { necrophorum } \\
\text { Bacteroides (not fragilis group) } \\
\text { Coliform }\end{array}$ \\
\hline 20 & Perianal abscess & ND & t. & - & $B$ ovatus & - \\
\hline 21 & Perianal abscess & + & + & - & $B$ fragilis & - \\
\hline 22 & Abdominal wound & ND & $\div$ & - & $B$ fragilis & - \\
\hline 23 & Anal fistula & ND & $-i$ & - & Bacteroides sp & Peptostreptococcus \\
\hline 24 & Peritoneal fluid & ND & + & - & - & - \\
\hline 25 & Pus Ca stomach & + & + & - & - & $\begin{array}{l}\text { Peptostreptococcus } \\
\text { Ps anaerobius } \\
\text { F nucleatum }\end{array}$ \\
\hline 26 & Axillary abscess & ND & + & - & - & Staph aureus \\
\hline 27 & Axillary abscess & ND & + & - & - & $\begin{array}{l}\text { B ureolyticus } \\
B \text { asaccharolyticus } \\
B \text { oralis } \\
P \text { prevotii } \\
B \text { asaccharolyticus }\end{array}$ \\
\hline 28 & Faecal fistula & ND & + & - & - & Coliforms $\times 3$ \\
\hline 29 & Abdominal wall abscess & - & - & + & $B$ thetaiotaomicron & P prevotii (2 types) \\
\hline 30 & Vulval abscess & ND & - & + & $\overline{-}$ & Microaerophilic strep \\
\hline 31 & Abdominal wound & ND & - & - & $B$ fragilis & Coliform \\
\hline 32 & Anal fistula & ND & - & - & Bacteroides sp & Coliforms $\times 2$, Proteus \\
\hline
\end{tabular}

+ positive. - negative. ND = not done. 
Table 3 Analysis of results of culture and IFA on 67 clinical specimens

\begin{tabular}{|c|c|c|c|c|c|c|}
\hline \multirow[t]{2}{*}{ Antiserum } & \multirow{2}{*}{$\begin{array}{l}\text { No of } \\
\text { specimens }\end{array}$} & \multirow[t]{2}{*}{$I F A$} & \multicolumn{2}{|l|}{ Culture } & \multirow{2}{*}{$\begin{array}{l}\text { Sensitivity } \\
\%\end{array}$} & \multirow{2}{*}{$\begin{array}{l}\text { Specificity } \\
\%\end{array}$} \\
\hline & & & Positive & Negative & & \\
\hline Barts' & 67 & $\begin{array}{l}\text { Positive } \\
\text { Negative }\end{array}$ & $\begin{array}{r}23 \\
3\end{array}$ & $\begin{array}{r}5 \\
36\end{array}$ & 88 & 88 \\
\hline Kit & 67 & $\begin{array}{l}\text { Positive } \\
\text { Negative }\end{array}$ & $\begin{array}{l}13 \\
13\end{array}$ & $\begin{array}{r}1 \\
40\end{array}$ & 50 & 98 \\
\hline
\end{tabular}

respectively. The predictive value of a negative IFA test (PV-neg) was $92 \%$ for Barts' antisera and $75 \%$ for the kit indicating that a negative IFA test with the Barts' antisera is a strong indicator of the absence of the $B$ fragilis group of organisms from the specimen.

The results of the GLC on 18 clinical specimens were correlated with IFA and culture results (Table 2). Eight specimens were positive by all three tests and culture, a further eight specimens were positive by GLC and culture and gave positive IFA with Barts' antisera, but gave negative results with the kit IFA test.

\section{Discussion}

If this technique is to be useful in a routine clinical bacteriology laboratory it is essential that it gives a reliable result within a few hours. The single stage staining procedure employed by the kit IFA significantly simplifies and shortens the test. However, this may be in part responsible for the low sensitivity $(50 \%)$ found in this study. The use of the rhodamineconjugated globulin prestain is intended to eliminate the theoretical problem of non-specific staining by staphylococci, streptococci etc which can bind the Fc segment of immunoglobulins. ${ }^{15} 16$ However this has not proved to be a problem in our experience; non-specific fluorescence differs in character and conformation.

The slides provided in the kit were found to be difficult to use. The inscribed circle within which the film is made disappeared fromview after themounting fluid was added, hindering the location of the specimen under the microscope. The use of Tefloncoated slides made the position of the film obvious and facilitated focusing on the specimen plane. The Teflon coating also prevented the reagents spreading off the film during incubation. The use of $\times 100$ oil immersion objective did not improve the sensitivity in this series but made reading of the slides more time-consuming.

The sensitivities were found to be less than in previous studies on the same antisera. ${ }^{9-11}$ The reasons for this are not obvious. The interpretation of fluorescence intensity is subjective but all readings were made by the same observer throughout the study and in the majority of cases this was checked independently by at least one other. Many of the isolates were identified only to the genus level. The low proportion of $\boldsymbol{B}$ fragilis or $\boldsymbol{B}$ fragilis group of isolates reported as Bacteroides sp may account for some of the false-negatives by IFA test. Observer error, sampling error in preparation of the film, and low number of organisms in the original specimen are other possible causes. The $B$ fragilis group of organisms possesses a multiplicity of antigens as demonstrated by the presence of various $\mathrm{O}$ serotypes. ${ }^{17-19}$ It is possible therefore that the presence of false-negative results is related to the lack of antigen used in raising the antisera. The Barts' antiserum, however, appears to cover more strains isolated from the two hospitals studied.

Positive reactions by immunofluorescence unsupported by a positive culture may be due to lack of viable organisms following antibiotic therapy or specimen transport difficulties. Isolates may go unrecognised on culture due to overgrowth by other organisms or failure to pick out all morphologically dissimilar colonies. Again, sampling errors may occur during specimen taking and inoculation of media. Cross-reactions with unrelated species would also give false-positive immunofluorescence, but no bacterial species was constantly grown from these specimens which was not also isolated from IFAnegative material. There were no cross-reactions with aerobic Gram-negative organisms isolated from these specimens.

Better correlation occurred with the results of GLC and Barts' IFA test than with the kit. Sixteen out of 18 specimens were positive by GLC and Barts' IFA test and on culture, whereas only eight of those were positive with the kit. GLC, although a useful adjunct in the rapid diagnosis of anaerobic infections, is only adaptable to specimens containing pus or fluid; also in mixed cultures, differentiation of species is not always possible. IFA can be applied to swabs as well as pus specimens and offers a sensitive and rapid test in less than two hours.

Rapid methods of bacterial detection are as yet no substitute for cultural methods. The use of immunofluorescence holds much promise but the choice of antiserum is of the utmost importance; geographical variations in prevalence of serotypes may exist 
between hospitals in the $\mathrm{UK}^{19}$ and it is possible that international variation may be even greater. Therefore, a suitable combination of antisera must be selected to be of such potency and have such crossreactions as to cover adequately the range of antigenic determinants found in the local strains of Bacteroides.

In this study, the kit antisera was found to be more specific and had a higher PV-pos $(93 \%)$ than the Barts' antisera (PV-pos $82 \%$ ), but this increased specificity was due to the presence of greater numbers of false-negative results. Hence, although it is much more likely to culture $B$ fragilis group of organisms from a specimen if the kit IFA is positive, it is also much more likely to miss a positive culture when the kit IFA is negative. On the other hand, the Barts' IFA test has a greater sensitivity, and because of the excellent predictive value of a negative test with the Barts' IFA test (PV-neg 92\%) compared with the kit IFA (PV-neg $75 \%$ ), it makes a negative result with the Barts' IFA test a good index of a negative culture. These findings, therefore, suggest that the Barts' IFA test is a reliable test to include in a routine clinical laboratory. A rational antimicrobial approach could be based on these results.

We wish to thank Miss Lorraine Hall for typing the manuscript.

\section{References}

${ }^{1}$ Finegold SM. Anaerobic bacteria in human disease. New York: Academic Press, 1977.

2 Barnstein DL, Weinberg AN, Swartz MN, Kunz LJ. Anaerobic infections-review of current experience. Medicine (Baltimore) 1964;43:207-32.

${ }^{3}$ Gorbach SL, Bartlett JG. Anaerobic infections. $N$ Engl J Med 1974;290:1177-84, 1237-45, 1289-94.

${ }^{4}$ Martin WJ. Isolation and identification of anaerobic bacteria in the clinical laboratory: a 2 year experience. Mavo Clin Proc 1974;49:300-8.

${ }^{5}$ Polk BF, Kasper DL. Bacteroides fragilis subspecies in clinical isolates. Ann Intern Med 1977;86:569-71.
${ }^{6}$ Coons AH, Creech HJ, Jones RN, Berliner E. The demonstration of pneumococcal antigen in tissues by the use of fluorescent antibody. J Immunol 1942;45:159.

- Lambe DW Jr. Determination of Bacteroides melaningenicus serogroups by fluorescent antibody staining. Appl Microbiol 1974;28:561-7.

${ }^{8}$ Stauffer LR, Hill EO, Holland JW, Altemeier WA. Indirect fluorescent antibody procedure for the rapid detection and identification of Bacteroides and Fusobacterium in clinical specimens. J Clin Microbiol 1975; 2:337.

${ }^{9}$ Kasper DL, Fiddian AP, Tabaqchali S. Rapid diagnosis of Bacteroides infections by indirect immunofluorescence assay of clinical specimens. Lancet 1979;i:239-42.

${ }^{10}$ Holland JW, Stauffer LR, Altemeier WA. Fluorescent antibody test kit for rapid detection and of members of the Bacteroides fragilis and Bacteroides melaninogenicus groups in clinical specimens. J Clin Microbiol 1979;10: 121-7.

${ }^{11}$ Labbé M, Delamare iN, Pepersack F. Detection of $B$ fragilis and $B$ melaninogenicus by direct immunofluorescence. J Clin Pathol 1980;33:1189-92.

12 Holdeman LV, Cato EP, Moore WEC. Anaerobic laboratory manual, 4th ed. Blacksburg, Virginia: Virginia Polytechnic Institute, 1977.

${ }^{13}$ Elhag KM, Tabaqchali S. A study of the surface and somatic antigens of Bacteroides fragilis. J Hyg (Camb) 1978;80:439-49.

11 Vecchio TJ. Predictive value of a single diagnostic test in unselected populations. $N$ Engl J Med 1966;274:1171-3.

${ }^{15}$ Forsgren A, Sjoquist J. Protein A from Staphylococcus aureus. J Immunol 1966;97:822.

${ }^{16}$ Peterson PK, Verhoef J, Sabath LD. Effect of protein A on staphylococcal opsonisation. Infect Immun 1977; 15:760-4.

${ }^{17}$ Beerens H, Wattre P, Shinjo T, Romond C. Premiers resultats d'un essai de classification serologique de 131 sonches de bacteroides de groupe fragilis (Eggerthella). Ann Inst Pasteur (Paris) 1971;121:187-98.

${ }^{18}$ Lamb DW, Moroz DA. Serogrouping of $B$ fragilis ss fragilis by the agglutination test. J Clin Microbiol 1976;3:486-592.

${ }^{19}$ Elhag KM, Tabaqchali S. The distribution of Bacteroides fragilis serotypes amongst clinical strains. J Hyg (Camb) $1978 ; 81: 89-97$.

Requests for reprints to: Dr Soad Tabaqchali, Department of Medical Microbiology, St Bartholomew's Hospital, London EC1A 7BE, England. 